\title{
Nota prévia sôbre a meiose de Corizus (Liorhyssus) hyalinus (Fabr.) (Hemiptera-Corizidae)
}

\author{
S. de Toledo Pisa Jor. \\ Professor de Zoologia, Anatomia e Fisiologia da Escola \\ Superior de Agricultura "Luiz de Queiroz", \\ da Universidade de Säo Paulo
}

Corizus hyalinus, num exame prévio do testiculo em orceina acética, pareceu-me constituir um bom material para estudo citológico, apesar de tratar-se de uma especle muito pequena. Porisso, fixei em Allen-Bouin os testículas de vinte individuos, incluí em parafina e preparei uma série de laminas, que foram coloridas pela hematoxilina de Heidenhain.

N\&o obstante a relativa abundancia do meu material, multa cousa permaneceu obscura, razko pela qual náo pọsso dar aqui senăo uma nota prévia. Alguns pontos, porém, foram estudados com suficiente clareza. 
Relativamente aos cromossómios espermatogoniais pude constatar que eles se comportam da maneira assinalada numa série de outras espécies, isto é, apresentam-se, na anáfase, fortemente recurvados para os pólos. (Fig. 1). (Cf. PIZA 1946, 1946a e PIZA \& ZAMITH 1946). Nenhuma placa metafásica em condiçoes de permitir uma exata contagem dos cromossómios foi encontrada. Aliás, como de regra, os cromossomios espermatogoniais fixam-se dificilmente. Nas melhores células foi possivel assinalar a presença de um volumoso plasmossómio e observar - o que me parece assás importante - que os cromossomios sáo tetradiformes, apresentando-se alguns com uma nitida constriçąo transversal. (Fig. 2).


Fig. 1 - Anáfase espermatogonial. (x5.400). Fig. 2 Metáfase de um espermatogónio, mostrando a constriçāo mediana dos cromossómios $(\times 5.200)$

Espermatócitos primários na fase leptotene e paquitene toram observados em grande número, se bem que fracamente coloridos. O cromossómio sexual mostra-se alongado e assoclado ao plasmossómio que se colore tao intensamente quanto ele, dificultando uma exata análise de suas mútuas relaçరes. 0 sexo-cromossomio apresenta-se frequentemente dobrado, parecendo provido de uma constriçăo transversal, ponto este que pretendo estudar mais acuradamente numa outra ocasizo. 
Os leptonemas e bem assim os paquinemas ficam na parte central do núcleo, năo se reconhecendo porisso a fase da sinizese.

Nas metáfases primárias o número de cromossômios fol determinado com facilidade. Encontram-se al 6 tétrades autossomais grandes dispostas em círculo, ficando no melo o cromossomio sexual, que é bem menor, e um par de diminutos microcromossomios. estes elementos nem sempre se apresentam com o mesmo tamanho, sendo um déles às vezes quase invisivel. (Fig. 3). Corizus hyalinus possui, pois, um par de autossomios a mais com relaçáo às espécies estudadas por MONTGOMERY (1901, 1906).

Os cromossomios pré-metafásicos apresentam-se formados por dois grossos cordóes paralelos, pareados segundo o seu comprimento, porém deixando no meio uma extensa abertura. ses bivalentes mostram-se geralmente dobrados pela regiáo mediana, dando algumas vezes aspectos perfeitamente comparáveis aos quiasmas que se observam nas meioses ortodoxas. (Figs. 5 e 6).

$\mathrm{Na}$ diacinese as tétrades assumem a forma já descrita para outros Hemipteros, isto é, apresentam-se formadas por dois blocos extremos nitidamente duplos no sentido longitudinal e ligadas por dois delgados cordoes que limitam a abertura mediana. As tétrades em forma de cruz săo inteiramente ausentes, o que quer dizer que năo há dobraduras nem torceduras na regiáo mediana, capazes de dar origem, por condensaçăo, aos braços laterais já descritos com referência a outras espécies e que costumam ser apontados como evidencia em favor do pareamento pelas pontas.

Os cromossomios se orientam, como em geral, com o malor eixo paralelamente ao eixo do fuso.

Figuras: anafásicas boas, foram raramente encontradas. Algumas, - porem, serviram para mostrar duas cousas: que o cromossomio sexual se divide transversalmente e que no final da anáfase, antes que as metades do sexo-cromossomio atinjam os pólas, já os autossomios podem se apresentar nitidamente duplos no sentido do seu maior eixo. (Fig. 4).

Segundo foi estabelecido em trabalhos anteriores para as diversas espécies que pude investigar, os cromossomios representados nas duas placas da Fig. 4 já se abriram segundo o plano de pareamento, ficando unidos pela extremidade acentrica, de maneira que a duplicidade longitudinal que se nota com tanta clareza deve-se a separaçáo dos cromatidios de cada cromossomio. 


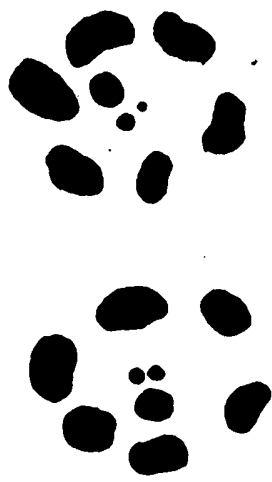

3

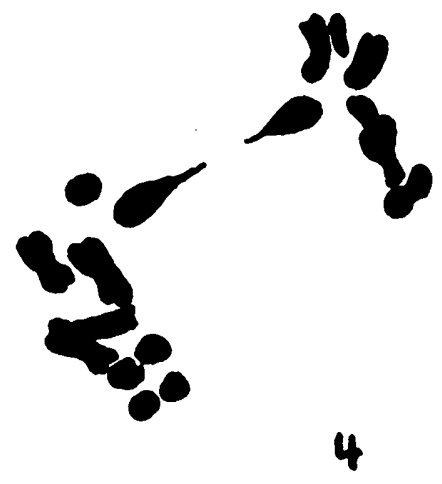

Fig. 3 - Dois espermatócitos primários em metáfase. Em cima, microcromossômios de tamanhos diferentes. (x6100). Fig. 4 -. Anáfase primária mostrando a divisão transversal do sexo-cromossómio e o aspecto quadripartido dos autossomios (6100)
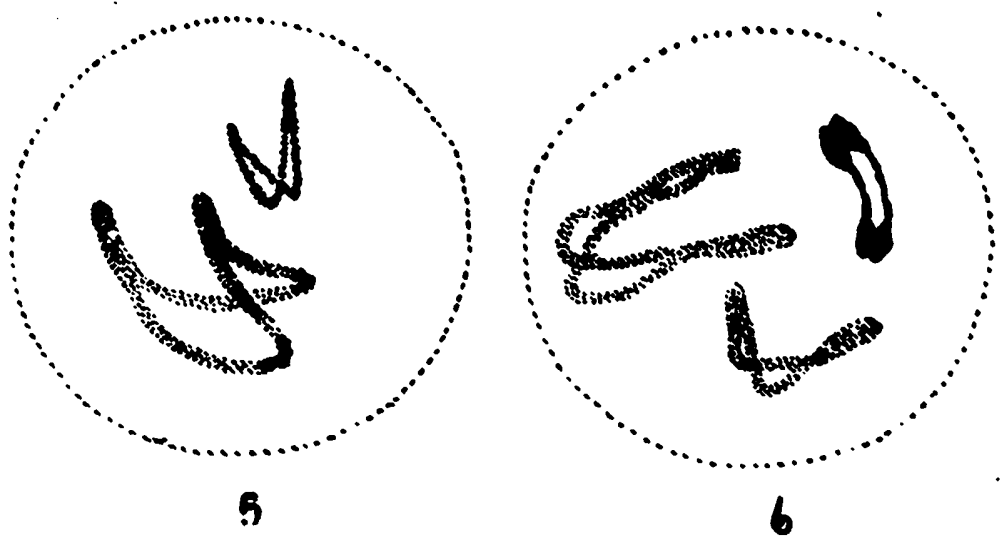

Figs. 5 e 6 - Bivalentes ainda longe da metafase, mostrando a grande extensão da abertura mediana ( $x 8000)$ 
Na segunda divisăo os autossómios novamente se orientam com o maior eixo paralelamente ao eixo do fuso e a divisăo é novamente transversal. A fenda longitudinal que separa os cromatídios năo é aí aproveitada e sim a constriçáo mediana que corresponde ao ponto de soldadura das extremidades após a abertura dos cromossómios pelo plano de pareamento, o que se processa da telófase primária para a metáfase da segunda divisăo.

O esquema abaixo (Fig. 7) permitirá compreender o que se passa com os cromossómios na meiose desta espécie e bem assim das outras precedentemente estudadas.

Em a temos dois leptonemas providos de um cinetocore em cada extremidade. Em b temos um bivalente, em c uma tétrade diacinética e em d uma tétrade metafásica. A anáfase primária representada em e mostra a tétrade se dividindo segundo um plano perpendicular ao plano de pareamento. Da telófase para a metáfase secundária $(\mathbf{f}, \mathrm{g})$ os cinetocores se afas-

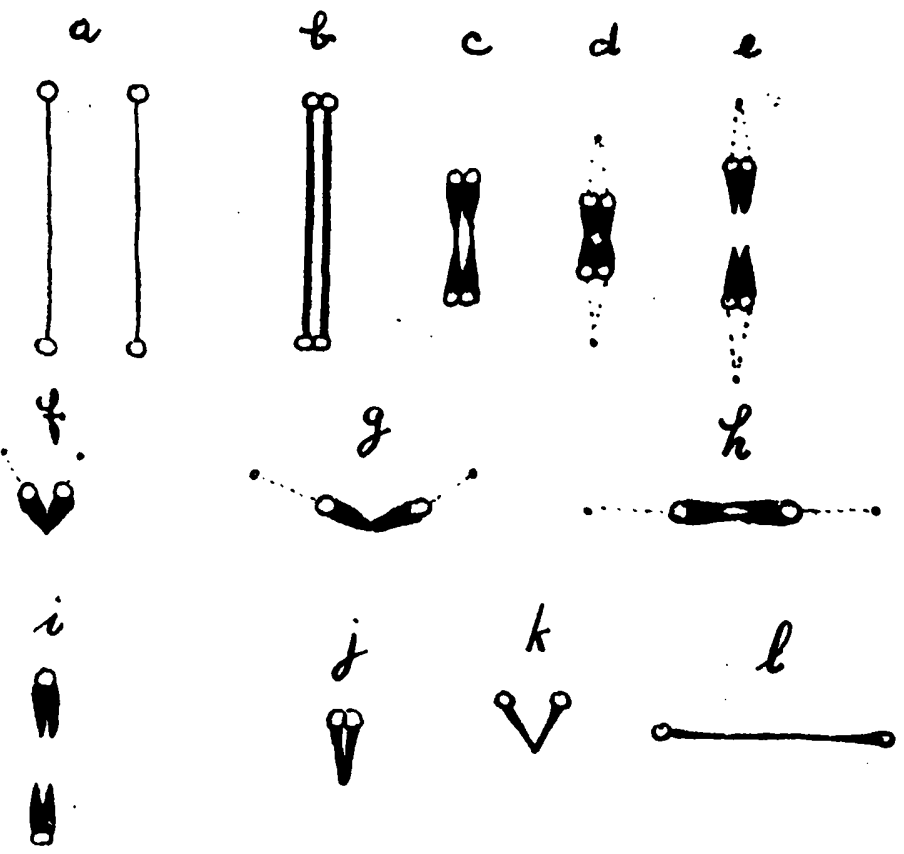

Fig. 7 - Esquema do comportamento dos cromossômios no meiose. (Explicação no texto) 
tam e os cromossómios se abrem segundo o plano de pareamento, ficando, porém, os dois elementos unidos pela extremidade acéntrica. isse movimento é, provàvelmente, influenciado pelo afastamento dos centrossômios. Em consequéncia disso, na metáfase da segunda divisăo, os cromossómios se apresentam novamente orientados com o seu maior eixo paralelamente ao eixo do fuso. (h). A fenda longitudinal que neles se observa corresponde ao plano de separação dos seus dois cromatidios. Na anáfase secundária completa-se a separação iniciada na prometáfase, indo para cada pólo dois cromatidios reunidos por um único cinetocore. (i). Provàvelmente na telofase secundária ou na prófase da primeira divisáo do óvo o cinetocore se divide e os cromatidios se separam a partir da extremidade centrica, ficando unidos pela extremidade acentrica. $(\mathbf{j}, \mathbf{k}, \mathbf{l})$. Assim se origina a dicentricidade assinalada nas células do embrizo. Ao se processar a meiose do novo ser, os fenomenos descritos se repetem, sendo que na primeira divisăo é que se completa a separaçáo dos cromatídios irmăos iniciada na melose da geraçăo precedente.

O cromossómio sexual, na segunda divisăo, comporta-se da maneira descrita para outras espécies: coloca-se com os autossomios na placa equatorial e na anáfase se distende como um corpo fusiforme, às vezes bastante longo. Passa para um dos pólos deixando no outro um dos cinetocores que pode ser acompanhado de um fragmento maior ou menor da extremidade respectiva. (Figs. 8, 9, 10 e 11).

O microcromossómio nas metáfases secundárias é extremamente pequeno e na maior parte das vezes inteiramente invisivel. Aqui está um ponto que requer novas investigaçøes. Pelo que me foi dado observar, os microcromossomios nesta especie parece que ainda se năo fixaram como estruturas definitivas, gozando de certa labilldade. Quero crer, à luz deste e de outros fatos observados nas espécies que tive ensejo de investigar, que nos encontramos na pista que conduzirá a solução do problema da origem dos microcromossómios. Como se sabe, ésses elementos variam consideràvelmente de volume, conforme as espécies, indo do limite da visibilidade até às dimensర̃es de pequenos autossómios. Porém, eles sempre se comportam como.sexo-cromossómios, quer dizer, são heteropicnóticos e se paream na metáfase, depois de condensados, tal como acontece com os cromossómios sexuais dos Hemípteros. Pode, porisso, bem ser, que no decurso da evoluçáo de uma dada espécle, o sexo-cromossomio usualmente perdia um fragmento centrico, provàvelmente de pequena viabilidade. Como a deficiencia re- 
sultante dessa perda pudesse prejudicar a espécle, um mecanismo desenvolveu-se, trabalhado pela seleçăo, cujo resultado fol, de um lado, a estabilizaçăo compensativa do microcromossómio e de outro, a faculdade que adquiriu o cromossómio sexual de passar para um dos pólos sem mais perder qualquer de suas extremidades,

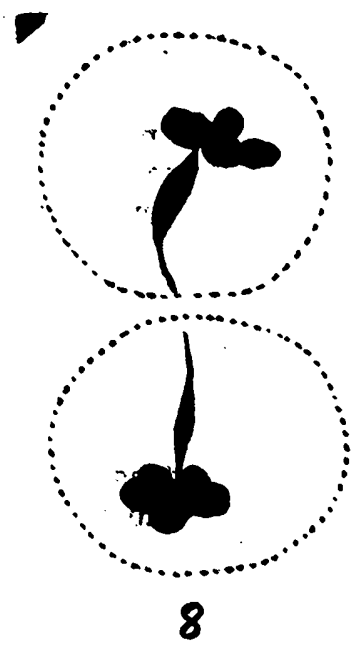

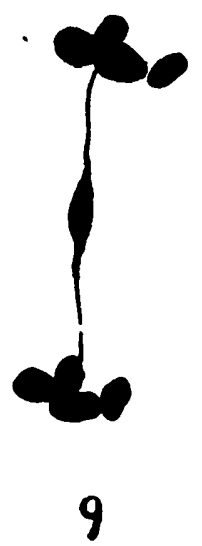
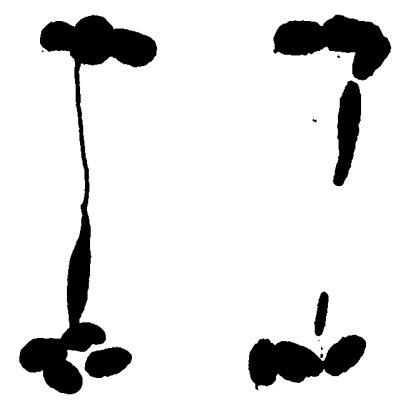

Figs. 8-11 - Anáfases da segunda divisão mostrando o comportamento

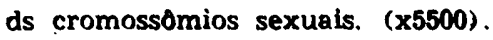

\section{SUMMARY AND CONCLUSIONS}

The main facts presented in this paper may be summarized as follows:

1) Corizus (Liorhyssus) hyalinus (Fabr.) has primary spermatocytes provided with 6 autosomal tetrads, one pair of microchromosomes and one sex chromosome.

2) The two microchromosomes present in this species sometimes appear at the primary metaphase as an unequal pair of minute elements. In the secondary spermatocytes the unique microchromasome present may be in the limit of visibility or entirely invisible. This invisibility may be partly due to a loss of colourability.

3) The sex chromosome divides transversely in the first division of the spermatocyte, passing undivided to one pole in 
the second one. In the latter it becomes fusiform in the beg:nning of anaphase revealing in this manner its dicentricity. In late anaphase it finishes by passing to one pole leaving in the other pole one of its kinetochores sometimes accompanied by a chromosomal fragment.

4) All the chromosomes divide transversely in both divisions, a diagram being enclosed to elucidate the question.

5) Spermatogonial chromosomes are provided with one kinetochore at each end, being curved toward the poles since the most beginning anaphase.

6) The following hypothesis is presented as an essav to explain the origin of microchromosomes: Since microchromasomes parallel sex chromosomes in most respects, as for instances in heteropycnosis and pairing modus, it seems highly probable that they originate from sex chromosomes. One may suppose that the ancestral form of a given species had a sex chromosome which used to lose a small centric fragment when it divided during meiosis. This fragment might well be at first an unstable one. Later, to compensate the effects of such a deficiency a mechanism arose through evolution which produced two useful results : a) the establishment of the fragment as a permanent structure of the cell nucleus and b) the acquirement by the sex chromosome of the faculty of passing to one pole without losing any of its ends.

\section{LITERATURA CITADA}

PIZA, S. de Toledo, Jor. 1946 - Comportamento dos cromossómios na meiose de Euryophthalmus rufipennis Laporte (Hemiptera-Pyrrhocoridae). An. Esc. Sup. Agric. "Luiz de Queiroz", 3: 27-54.

PIZA, S. de Toledo, Jor. 1946 - Notas sôbre a melase de $\mathrm{Pa}$ chylis (Hemiptera-Coreidae) An. Esc. Sup. Agric. "Luiz de Queiroz", 3: 55-67.

PIZA, S. de Toledo, Jor. e A. P. L. Zamith, 1946 - Provas adicionais da dicentricidade dos cromossómios dos Hemipteros. An. Esc. Sup. Agric. "Luiz de Queiroz" 3: 90-97.

MONTGOMERY, T. H. 1901 - Further studies on chromosnmes of Hemiptera Heteroptera. Proc. Acad. Sc. Philadelphia. 53: 261-271.

MONTGOMERY, T. H. 1906 - Chromosomes in the spermatogenesis of the Hemiptera Heteroptera Tras. Am. Phil. Soc. 21: $97-174$. 